\title{
Notas de un conversatorio sobre la traducción literaria en Centroamérica ${ }^{1}$
}

\author{
Sherry E. Gapper ${ }^{2}$
}

Universidad Nacional, Costa Rica

Victor S. Drescher ${ }^{3}$

Indiana University of Pennsylvania, Estados Unidos

Francisco Vargas Gómez ${ }^{4}$

Universidad Nacional, Costa Rica

\begin{abstract}
resumen
Es la transcripción de sendas participaciones, sobre traducción y traductología, referidas a tres aspectos principales: el desarrollo de esa actividad en Centroamérica (Gapper), el ejercicio práctico en un corpus (Drescher), y la proyección y perspectivas en la región (Vargas). Se señalan asuntos de índole histórica, teórica, y practica, con el fin de sistematizar la evolución de esa disciplina, en particular en el ámbito de la academia.
\end{abstract}

\begin{abstract}
This is the transcription of the corresponding interventions, on translation and translation studies, regarding three main aspects: the development of the activity in Central America (Gapper), applications in a particular corpus (Drescher), and the projections and perspectives in the region (Vargas). Historical, theoretical and practical issues are addressed, in order to systematize the development of this discipline, particularly in academic spheres.
\end{abstract}

1 Notas de un conversatorio sobre la situación actual, experiencias y perspectivas de la traducción literaria en Centroamérica, coordinado por Judit Tomcsányi, en el XX Congreso Internacional de Literatura Centroamericana (ciLca) 2012. Recibido: 30 de marzo de 2011; aceptado: 22 de abril de 2011.

2 Escuela de Literatura y Ciencias del Lenguaje. Correo electrónico: sgapper@una.ac.cr

3 Profesor emérito. Correo electrónico: drescher@windstream.net

4 Escuela de Literatura y Ciencias del Lenguaje. Correo electrónico: saussurre2@gmail.com

$$
L_{\text {etras }} 49 \text { (2011), ISSN 1409-424X }
$$


Palabras clave: traducción literaria y traductología, historia de la traducción, traducción de poesía, tendencias contemporáneas en traducción, literatura costarricense

Keywords: literary translation and translation studies, translation history, translation of poetry, contemporary tendencies in translation, Cos- ta Rican literature

En el XX Congreso Internacional de Literatura Centroamericana se dedicó uno de los temas a las relaciones de esa literatura con diversos entornos: los históricos, los culturales, los literarios. En ese marco se consideró que la traducción debía plantearse como un asunto de particular importancia, puesto que representa una manifestación significativa de una forma específica de diálogo: el que se establece entre lenguas. También, claro está, hay otros tipos de contactos, fraternidades y sociedades: las herencias literarias, las respuestas; pero poco se ha dicho sobre los contactos - mediados por la traducción - de esta literatura regional con otros universos lingüísticos.

Se ofrecen aquí las exposiciones de varios traductólogos, quienes desde perspectivas y asuntos específicos se refieren a la evolución, situación actual y perspectivas de esta actividad. Cada uno de ellos cuenta con amplia experiencia y una importante labor en la promoción de los estudios sobre traducción, especialmente desarrollada en la Universidad Nacional (UNA), de Costa Rica.

La actividad, en la modalidad de mesa redonda, se efectuó el 29 de marzo de 2012, y estuvo coordinada por la profesora Judit Tomcsányi, lingüista y traductora, que forma parte del cuerpo académico de la Universidad Nacional, organizadora y sede del mencionado congreso. 


\title{
I. La situación, las experiencias y las perspectivas de la tra- ducción literaria en Centroamérica
}

\author{
Sherry Gapper
}

\section{Aclaraciones conceptuales básicas}

Quisiera empezar por aclarar, brevemente, tres asuntos a los que me voy a referir. Por una parte, que me pareció muy oportuna y adecuada la decisión de los organizadores de este congreso de incluir un tema esencial del se habla relativamente poco: las relaciones de la literatura centroamericana con otras tradiciones literarias, y más particularmente con otros idiomas. En segundo lugar, que la traducción como disciplina y como actividad debe incluirse dentro de estos temas, porque a lo largo de su historia, una porción significativa de las letras centroamericanas ha sido traducida para difundirse en otros ámbitos geográficos y culturales. Y en tercer lugar, considero que no debemos entender la traducción como una simple técnica de poner en otro idioma «lo que quiso decir» su autor en la lengua original. Ante todo, la traducción es un acto y una voluntad de comunicación, y cuando hablamos de la traducción literaria tenemos que agregar un factor más, de especial importancia: es poner en comunicación no solo dos lenguas, sino dos literaturas y, en último término, dos culturas e incluso dos tradiciones históricas. Es, como lo estamos haciendo ahora mismo, ponernos a conversar y a encontrar puntos en común.

Ahora bien, la traducción literaria da mucho de qué hablar, sobre todo si se tiene en cuenta que el contacto entre idiomas no solo es un asunto circunstancial (por ejemplo, por conveniencia del mercado editorial), sino que tiene que ver con la necesaria ampliación del conocimiento de estas letras regionales, lo que incluye hablantes o lectores que, simplemente, no conocen el castellano. 


\section{Las cinco situaciones en la traducción}

Hay, como seguramente todos sabemos aquí, al menos cin- co situaciones en la traducción literaria, situaciones comunes en Centroamérica:

1. Cuando hay traductores extranjeros que han vertido obras literarias centroamericanas a sus idiomas respectivos;

2. Cuando hay traductores (incluidos escritores) centroamericanos que traducen literatura extranjera al español (por ejemplo, de autores llamados «clásicos»); [endotraducción]

3. Cuando hay traductores centroamericanos que traducen literatura centroamericana a otros idiomas (lo que técnicamente se conoce como traducción inversa); [exotraducción]

4. Cuando hay traductores centroamericanos que traducen textos nacionales escritos en lenguas indígenas o en lenguas criollas, al español (por ejemplo, para difundir aspectos de las culturas aborígenes entre quienes no conocen sus lenguas); y

5. Cuando hay más bien traductores extranjeros que traducen textos nacionales escritos en lenguas indígenas o en lenguas criollas, a otros idiomas.

\section{Algunas de esas situaciones para su comentario}

Por supuesto, no podría referirme aquí a cada una de esas opciones. Sí les puedo decir que estas situaciones se han dado en Centroamérica. Por ejemplo, podemos señalar algunos casos de la situación 2 (es decir, la de traductores centroamericanos que traducen literatura extranjera al español). Aquí, en Costa Rica, contamos con algunos ilustres escritores que han realizado notables trabajos de traducción de obras, digámoslo así, «clásicas». Mencionemos algunos nombres: Ricardo Fernández Guardia, Carlos Gagini, (traductor de Victor Hugo, Longfellow y Lord Byron), Roberto Brenes Mesén (traductor de autores tan diversos como Maurice Maeterlinck, Paul 
Geraldy, Stecchetti, Krisnamurti o Gibrán), José Basileo Acuña (traductor de poesía francesa e inglesa, especialmente de Shakespeare), Joaquín Gutiérrez (también buen traductor de Shakespeare), y varios autores contemporáneos como Rodrigo Quirós, Carlos Rafael Duverrán, Ricardo Ulloa Garay, Alicia Miranda Hevia o Rafael Ángel Herra. Sabemos ya, incluso, de jóvenes escritores que practican la traducción hoy día como el joven poeta costarricense Luis Chaves.

\section{Algunos ejemplos de las lenguas clásicas, en Costa Rica}

Debo mencionar un caso muy notable, el del profesor y latinista Faustino Chamorro González, quien en 1987 publicó su traducción rítmica al castellano (del latín), de Rusticatio mexicana, de Rafael Landívar, ilustre poeta guatemalteco del siglo xvi. Me refiero con particular atención a este caso porque ese trabajo de traducción se originó aquí mismo, en esta Facultad de Filosofía y Letras; fue la tesis con la que Chamorro se recibió de doctor en la Universidad de Salamanca. Además, Chamorro se había interesado ya en la presencia y el uso del latín en Costa Rica, como lo dejó documentado en su libro Inscripciones latinas en monumentos costarricenses, publicado en 1979. Y si de textos en lenguas clásicas hablamos, habría que mencionar trabajos como el de Constantino Láscaris, filósofo español que se afincó en Costa Rica, quien tradujo del griego, entre otras obras clásicas, Sobre la naturaleza, de Heráclito, que publicó en 1976.

\section{La traducción desde Centroamérica}

La llamada exotraducción - es decir, la actividad de traducción desde nuestros países - también arroja algunos datos dignos de comentar aquí. Consideremos dos de las posibilidades: la de traductores del «exterior»; es decir, de otros países donde no se habla el español, que se han interesado por autores y obras literarias particulares de Centroamérica [situación 1], y la de traductores nacionales, que desde nuestros países han emprendido la tarea de traducir aquí y, cuando les ha sido posible, publicar en el exterior [situación 3]. 
Naturalmente, hay grandes nombres en las letras centroamericanas que, con sobrados merecimientos, han sido traducidos a otras lenguas: Rubén Darío, Miguel Ángel Asturias (estimulado, en este caso, por el premio Nobel que recibió en 1967), Rafael Arévalo Martínez, Claudia Lars, Ernesto Cardenal, Manlio Argueta, Roque Dalton, Otto René Castillo, Roberto Sosa, Claribel Alegría, Humberto Ak'abal, Jacinta Escudos, Sergio Ramírez, Gioconda Belli, y seguramente muchos más. Si nos detenemos en Costa Rica, podemos mencionar un número nada despreciable de autores cuya obra ha sido traducida; empezando por el célebre novelista Carlos Luis Fallas (traducido a muy diversas lenguas), y junto a él hay importantes traducciones de obras de Carmen Lyra, José León Sánchez (de cuya obra ya hay, según tengo noticia, traducciones incluso al chino), Fabián Dobles, Quince Duncan, Carmen Naranjo, Laureano Albán, Ana Istarú, Anacristina Rossi, Fernando Contreras, Rafael Ángel Herra, Tatiana Lobo, Samuel Rovinski y Lara Ríos. Aquí mismo, en esta sala, está con nosotros otro traductor, nuestro colega y profesor visitante Victor Drescher, que desde hace muchos años se ha interesado por las letras costarricenses, especialmente la poesía, que ha vertido al inglés.

La traducción desde lenguas indígenas: el caso de las lenguas chibchenses, y uno de la maya quiché; o de lenguas criollas

Pero no hay que olvidar aquí una rama de la traducción sobre la que no se habla mucho: la traducción de textos de lenguas indígenas chibchenses. En Costa Rica se destacan - probablemente porque son casos únicos - los trabajos hechos por lingüistas como Adolfo Constenla Umaña y Enrique Margery Peña. Constenla ha traducido poesía tradicional indígena, del guatuso, del bribri, del guaimí y del boruca. Margery Peña llevó a cabo estudios de mitología comparada y emprendió un valioso trabajo de interpretación de leyendas, tradiciones y mitos, que vertió al castellano. 
También es interesante la experiencia de Humberto Ak 'abal, el poeta guatemalteco contemporáneo que acabo de mencionar, quien escribe sus poemas en maya quiché y él mismo se encarga de traducirlos al español. Y en cuanto al criollo de Limón, existen, por ejemplo, traducciones de unos cuentos criollos del hermano Araña (Anancy Stories).

\section{El caso de las experiencias desarrolladas en el PMT, durante los últimos veinte años}

Ahora bien, por tener un conocimiento más claro y cercano del caso de Costa Rica, voy a referirme a las experiencias más recientes que se han alcanzado en nuestro medio, especialmente desde la fundación de un programa de estudios académicos de traducción. Ya en la Escuela de Literatura y Ciencias del Lenguaje —organizadora de este Congreso - se está a punto de cumplir veinte años desde que se impulsó la carrera de traducción profesional, entre sus programas. Por razones más bien administrativas y de estrategia funcional, se denomina Plan de Maestría en Traducción, aunque bien podría hablarse ya de un Instituto de Traducción e Interpretación. Pero eso será un asunto que podremos considerar en el mediano plazo.

Aunque está abierto a todas las especialidades y áreas de conocimiento, el campo de la traducción en nuestro programa ha dejado un amplio espacio a la traducción literaria. Hay, como cabe suponerse, numerosos casos de estudiantes graduados nuestros que se han inclinado por la endotraducción; es decir, verter al español obras literarias (poesía, teatro, narrativa) escritas originalmente en otros idiomas, principalmente del inglés. Pero también hemos tenido la grata experiencia de saber que entre nuestros graduados hay quienes se interesaron por traducir obras literarias costarricenses a otras lenguas (la exotraducción). Creo que vale la pena detenerse en estos casos, no solo por sus méritos particulares, sino por el significado que ello tiene desde el punto de vista cultural. Haciendo un recuento, 
tenemos, entre otros, los siguientes: Limon Blues, de Anacristina Rossi (traducido por Susana Starcevic); En una silla de ruedas, de Carmen Lyra (traducido por Georgina Alvarado); Cuentos de angustias y paisajes, de Carlos Salazar Herrera (traducido por María Luz Méndez); El ímpetu de las tormentas, de Alberto Sibaja (traducción de Natalia Robles); La ruta de su evasión, de Yolanda Oreamuno (traducción de Danielle Kampffer); y Francisco y los caminos, de Francisco Amighetti (traducido por Elena Montero). Están en proyecto estudios para la traducción de obras de Fernando Contreras, Carlos Luis Fallas (Marcos Ramírez) y de Aquileo J. Echeverría (Concherías), entre otros.

\section{Programas académicos de traducción en Centroamérica}

Me he limitado al caso de Costa Rica, en primer lugar, porque dispongo de más datos documentados, pero también porque no tengo aquí reunida información pública suficiente de los otros países centroamericanos en esta materia. La Universidad Nacional es la institución académica que se ha empeñado en desarrollar sistemáticamente la traducción como disciplina y como actividad profesional. Cuenta en la actualidad con un programa de posgrado en traducción, para la formación de traductores profesionales. No es la única; aclaremos: por ejemplo, la Escuela de Ciencias Lingüísticas, de la Universidad de San Carlos de Guatemala ofrece una carrera en Traducción y Correspondencia Internacional; y el Departamento de Lenguas Extranjeras de la Universidad de El Salvador también tiene un programa similar al nuestro. Pero, en términos generales, se echa de menos en la región una actividad sistemática, de parte de los centroamericanos, por la exotraducción. Son relativamente abundantes las recopilaciones y antologías - aparte de obras particulares de autores - de literatura centroamericana traducida. Con relativa facilidad podemos localizar recopilaciones (bilingües o no) de traducciones al alemán, al francés, al inglés, al italiano. Pero de ello se han encargado de 
manera algo azarosa las editoriales universitarias de los Estados Unidos, Alemania, Francia o Gran Bretaña, o bien algunas editoriales, también del exterior, interesadas en su comercialización. Lo cierto es que las letras centroamericanas se están traduciendo cada vez más, sobre todo la contemporánea.

Nuestra región cuenta ya con autores de indudable prestigio y reconocimiento internacionales, y no solo los «clásicos» como Darío, Asturias o Cardenal. Puede que eso esté asociado a las grandes firmas transnacionales (o sellos editoriales, para decirlo con elegancia) interesadas en sacar partido de lo que aquí se produce, pero con ello la actividad traductiva también se ha incrementado.

¿Por qué no pensar también en que nosotros mismos nos vayamos encargando de traducir esa literatura desde aquí mismo; como si dijéramos, desde nuestra propia casa? Pues bien, algo de eso nos hemos querido proponer nosotros aquí mismo, desde el Plan de Maestría en Traducción que estamos desarrollando en esta casa deestudios.

He notado que, en general, que cuando un traductor nacional traduce una obra literaria costarricense a otra lengua, suele detenerse o preocuparse mucho más que el traductor extranjero por conservar u comunicar al nuevo destinatario (el lector no hispanohablante) lo que considera propio o peculiar de la cultura nacional: en cambio, el traductor extranjero revela dos características: o no conoce lo suficiente de los aspectos de la cultura costarricense, o no le da la misma importancia.

\section{Conclusiones}

Mi tesis es la siguiente: la traducción no tiene por qué entenderse como una simple versión de un texto de una lengua a otra. A diferencia de ello, la traducción es un contacto entre culturas, entre sendas realidades construidas desde los idiomas. Cuando unos lingüistas costarricenses, como los que he mencionado, han traducido canciones y poemas borucas o bribris, no han hecho otra cosa que poner a dialogar dos culturas, a través de la palabra poética. La experiencia 
de los traductores contemporáneos, que se han dedicado a traducir las letras nacionales, es también digna de destacarse. Detrás de todo ello, hay un afán por poner nuestras creaciones culturales en relación con otras culturas y otras regiones, otros mundos lingüísticos: el alemán, el francés, el inglés, el portugués, lenguas contemporáneas que, en cierta medida, también se enriquecen con estos aportes, porque los idiomas y sus literaturas se enriquecen con las traducciones, como sobradamente se ha demostrado a lo largo de lahistoria.

\section{Un caso particular: una antología bilingüe de poesía costarricense $^{5}$}

Victor S. Drescher

\section{¿Por qué traducir poesía costarricense?}

Empiezo con una pregunta retórica que no es, al fin y al cabo, una pregunta para todos, porque la he tenido que contestar aquí en Costa Rica más de una vez. Y siempre la contesto de la misma manera: porque es una poesía increíblemente rica, una poesía de primera clase, que merece el público más amplio posible.

\section{El origen de la antología}

Fue esta confianza en el mérito de la poesía costarricense la que nos llevó a preparar una antología. Hace ya tres años que un poeta costarricense, Carlos Francisco Monge, tuvo la idea de que podríamos, entre nosotros, elaborar una antología bilingüe de poesía costarricense contemporánea. Monge y yo nos conocimos durante mi primera visita en Costa Rica en 1990 y no sería la primera vez que trabajáramos juntos. En 2002, tuve la ocasión de traducir su libro de poesía La tinta

5 Carlos Francisco Monge (Comp.) y Victor S. Drescher (Trad.), Contemporary Costa Rican Poetry (Heredia, C.R.: Escuela de Literatura y Ciencias del Lenguaje/Indiana University of Pennsylvania, 2012). 
extinta, así que sabíamos por experiencia propia que podemos trabajar juntos. Invisible Ink fue publicado en 2006, fruto de la colaboración entre la Universidad Nacional y mi Universidad, IUP.

\section{La organización del trabajo}

La división de labores en este proyecto fue totalmente lógica y evidente. Yo hago la traducción y Carlos Francisco hace el resto. Él hizo la selección de los poetas y los poemas, y, bien pensado, como el mismo es miembro de este club de élites, éste no podía ser muy fácil. Imagínese; hacer una selección semejante me parece cuestión de reconocer la obra de un colega y no reconocer la de otro. Y como son, en muchos casos, escritores que Carlos Francisco conoce personalmente, a veces tuvo que tomar decisiones difíciles, no cabe duda. Pero, a fin de cuentas, hizo la selección y la hizo de una manera magistral, regalándonos una gama tremendamente variada y rica de temas, de voces, de estilos y de estéticos. Quisiera darles un breve vistazo de los contenidos.

\section{Contenidos de la antología}

Claro está que el amor, tema benemérito de la poesía desde siempre, se trata en varios casos. Carlos Rafael Duverrán nos comunica el amor del padre por la hija en su «Retrato de niña»; y Jorge Charpentier da un ejemplo conmovedor del amor y de la admiración por la madre en su vejez en su poema «Con el bastón...». El amor erótico es el tema de Julieta Dobles en «La casa enamorada» y también para Ana Istarú en su poema «De dónde has llegado». Su poema «Ahora que el amor...» adopta una perspectiva diferente del primero, pero también resulta un poema relativamente erótico. Mientras que «Ábrate sexo» no tiene nada erótico. La poeta está dando a luz y está animando a su vagina a que se abra. Es un poema fascinante. Lo digo en serio; toda mujer que ha experimentado el parto debe leerlo. 
Esta colección abarca temas universales en la literatura, tan universales como el Quijote. Pero aquí el poema, «Profanación del Quijote», del propio poeta Monge, toma la perspectiva del docente frente a un grupo de adolescentes a quienes debe explicar, comunicar, convencer para decirlo de una vez, de la importancia del Quijote. Y le resulta difícil cuando el poeta mismo se llama una cantera de dudas y trata al Caballero de la Mancha como un tonto de capirote.

Aunque los temas universales de la poesía abundan en esta antología, también aparecen temas y sujetos particularmente ticos. Es Mía Gallegos en «El claustro elegido» que escribe Mi patria, montaña verde y lluvia. Y ¿qué tico no entiende a Isaac Azofeifa, cuando escribe un poema con el título «El yigüirro de la madrugada»?

\section{Consideraciones teóricas}

Hemos empezado por contestar la pregunta, «¿Por qué traducir poesía costarricense?» Para mí, ésa es la pregunta más fácil. Después hemos visto el tema, «¿Qué poesía costarricense traducir?»; y como respuesta de esta pregunta hemos explorado los contenidos de la antología. Pero la tercera es la más complicada. Para continuar con una organización a base de preguntas retóricas, la tercera sería, posiblemente, «¿Cómo traducir la poesía costarricense?»

Mi respuesta se basa, naturalmente, en mi concepto de la traducción de poesía. En mi opinión, traducir poesía es crear poesía. De todas las categorías de traducción que se pueden hacer, que sea traducción de textos legales, de textos comerciales, de textos turísticos, y otros más, la traducción de poesía es la más libre, la más creativa de todas.

Efectivamente, para tomar un caso concreto, el «Poema del encino» es un poema de Carlos Francisco Monge. Pero la traducción que hice de esta obra tiene el título «The Oak» y es mi creación. El poema «The Oak» debe su existencia a mi acto creativo. Si yo no hubiera traducido «Poema del encino», no habría poema en esta antología con el título «The Oak». 
Ahora bien, ¿qué le debo al autor? Hay muchas opiniones sobre el asunto, numerosas escuelas, muchas teorías, que varían muchísimo. Para mí, como traductor, mi filosofía en cuanto a mi deuda al poeta es la siguiente. Tengo que hacer todo lo posible para comunicar el mensaje del poema original al lector del poema traducido al inglés. No puedo traducir «Poema del encino», un trabajo bastante abstracto sobre la condición humana, como si tratara de la belleza de las bellotas y como nutren los ciervos en la selva. Eso sería intelectualmente fraudulento, y todos lo sabemos. Eso fue una exageración, claro, pero una exageración de manera de ilustración. Mi criterio es que el traductor de poesía tiene que ser fiel al mensaje del poema original.

Esto es evidente. Pero después de este punto de partido, a lo largo del camino, hay un sin fin de decisiones que tomar que no son tan evidentes. Si la meta de mi traducción es comunicar el mensaje del poeta, ¿es necesario, por ejemplo, imitar la distribución de las palabras en la pagina?

Julieta Dobles escribe su poema «Descubrimiento» al margen derecho de la página. ¿Qué tan importante es esto? ¿Tengo derecho a cambiarlo y escribir mi poema «Discovery» en el margen izquierdo como consideramos «normal» en el occidente?

$\mathrm{O}$, ¿tenemos que imitar la puntuación del autor? Carlos Cortés, por ejemplo, en su poema «Peregrinación del aguafiestas», no utiliza puntuación del todo, pese a que le vendría muy bien un par de comas de vez en cuando para una mejor comprensión de su poema. ¿Tengo yo, humilde traductor, el derecho de añadirlas en mi poema? ¡Claro que sí! Para mí, la puntuación facilita la lectura del poema y yo la pongo gratis, sin costo adicional.

Estas son las decisiones más fáciles de tomar. Hay ocasiones cuando la traducción requiere cambios más importantes en la organización de la frase o en las imágenes utilizadas. A veces lo que sí funciona en un idioma no sale bien en otro, no suena. Veamos unos ejemplos en el poema «Tiempo de danzar» de Mía Gallegos. Vamos a centrarnos solamente en los tres primeros renglones: 
No, Yo no me ato al tiempo perecedero.

Busco más bien

El otro tiempo, el del ropaje intimo.

¿Cómo vamos a traducir Busco más bien el otro tiempo, el del ropaje intimo? Esto del ropaje íntimo no se puede traducir así al inglés, simplemente no funciona, no se entiende. En este verso ninguna traducción de esa prenda, que sea undergarment, intimate apparel, o aun peor underwear, sería admisible. Suena demasiado raro. En estos casos, hay que buscar un subterfugio. Esto es más complicado para Uds. como no tienen todo el texto, pero deben saber que en este poema Mía Gallegos hace referencias a Cressida, de la mitología griega, y se dice griega, y habla del tiempo de los dioses. Por eso, yo prefiero un vocabulario más de aquella época. En vez de traducir ropaje intimo como undergarment, intimate apparel o underwear, me imagino algo distinto, y digo flowing robes, que, en todo caso, me parece mucho más poético que underwear.

Pero hay más. El verbo busco - recuerdan el verso: Busco más bien el otro tiempo, el del ropaje intimo - me permite añadir la imagen hidden behind, que no se encuentra en la obra original, pero que complementa muy bien la imagen de flowing robes, y contribuye al ambiente del mundo misterioso de la antigüedad donde vivía Cressida. Así que, el verso, Busco más bien el otro tiempo, el del ropaje intimo, se traduce así: I am searching for the other time, the one hidden behind flowing robes.

Otro ejemplo semejante sería el de «Ahora que el amor», de Istarú. Aquí el problema radica en una diferencia entre el léxico anglosajón de símbolos y el léxico hispano. En el poema, Ana Istarú se queja de como el amor, la idea, la noción del amor, ha cambiado últimamente. El poema es un poco largo; voy a citar solo los versos en cuestión: ... se palpan varón y mujer sin alcanzar el mirto. Ahora bien, si bien es cierto que la palabra mirto es símbolo del amor romántico/físico en español, no lo es en inglés. En el idioma 
de Shakespeare el símbolo más frecuente por el amor es la rosa, una rosa roja en particular. Entonces en este caso la traducción exige una sencilla substitución de símbolos. Y traducimos: sin alcanzar el mirto como but fail to reach the rose.

Para terminar, quisiera decir unas palabras sobre la importancia de los sonidos. Al fin y al cabo, se trata de poesía y los sonidos aquí son mas importantes que en la prosa. Afortunadamente la poesía moderna se escribe en lo que llamamos "versos libres," donde no tenemos que contar silabas ni rimar vocales. Pero cuando sea posible, yo hago un esfuerzo al nivel de los sonidos. En el ejemplo de Ana Istarú que acabamos de ver, el verbo fue alcanzar, en... alcanzar el mirto.

El sentido literal de alcanzar es attain. Habría sido perfectamente factible traducir ese verso como: ... but fail to attain the rose. Pero como ya hemos decidido cambiar mirto a rose (con $\langle\mathrm{r} »)$, en mi opinión, but fail to reach the rose, con la repetición de la «r», suena mejor. Sin alcanzar el mirto: But fail to reach the rose.

Otro es el caso de un poema de Monge, «El encino», donde me divertí convirtiendo Ansiedad y esplendor, contemplación y fuga I Un claror, y un rumoroso aroma en both anxiety and delight, contemplation and flight / a flash of light and a murmuring aroma.

Hablando de sonidos, hay también combinaciones de sonidos que es mejor evitar. Recuerdo muy bien que cuando estaba traduciendo de Carlos Francisco Monge, La tinta extinta, cuyo título no se podía traducir literalmente porque soñaba demasiado raro: la tinta extinta ... extinct ink, extinct ink suena demasiado como stink... stink ink, ... ink stinks; no importa como se organiza, ¡huele mal como titulo! así que opté por el titulo Invisible Ink, que también puede justificarse si se hae un análisis del contenido.

Para mí, es así que se traduce la poesía, verso por verso, palabra por palabra, imagen por imagen, tomando todo en cuenta y tomando miles de decisiones pequeñas. 


\section{Perspectivas de la traducción literaria en Centroamérica: tareas traductológicas pendientes}

Francisco Vargas

\section{Contextualización}

Voy a referirme a la cuestión de las perspectivas traductológicas en el campo de la traducción de las letras centroamericanas, en un intento de delimitar algunas tareas todavía pendientes. Antes de emitir cualquier opinión sobre la dirección que deberían tomar los estudios traductológicos sobre el tema de la traducción literaria en Centroamérica, pienso que es necesario realizar algunas acotaciones a manera de contextualización. Tales ideas pretenden ubicarnos con respecto a la actualidad de los Estudios de traducción dentro del área centroamericana.

Debo aclarar que al exponer estas primeras ideas, sobre el estado del arte de la actividad traductológica en el área centroamericana, parto de mis conocimientos sobre el caso de Costa Rica, y de algunas observaciones y datos preliminares relacionados a la situación traductológica de otros países de la región. Me he atrevido a suponer que el caso costarricense es representativo de la situación en los restantes países del istmo. De no ser así, pido disculpa anticipadas.

Pues bien, las letras centroamericanas han tenido grandes representantes, muchos de los cuales han logrado incursionar en espacios que están más allá del límite de las fronteras de los países que integran esta región. Algunos más, incluso, han cruzado con mucho éxito las barreras de la lengua arribando a contextos lingüísticos tan variados como el ruso, chino, sueco, rumano y hebreo, entre otros. Esto para no mencionar las publicaciones que han surgido en lenguas que no nos parecerán tan "ajenas" como el francés, italiano, alemán e inglés.

Estos hechos implican que la traducción, en tanto práctica y productos, ha vehiculado la migración de determinadas obras y 
autores centroamericanos - no tantos como quisiéramos, dicho sea de paso- - Sin embargo, al mismo tiempo hemos instaurado la penosa tradición de no poner la adecuada atención a este fenómeno, al menos no desde el punto de vista traductológico. Es cierto que en diversas ocasiones no se pasa por alto, al menos no del todo, el que alguno de nuestros escritores sea traducido a esta o aquella lengua. Pero el interés - momentáneo - que se presta usualmente no va más allá de saber qué y a quién se tradujo. Se lanza una que otra exclamación de asombro y orgullo, y luego la experiencia es archivada como en tantas otras ocasiones. En el mejor de los casos, el asunto será retomado, las más de las veces desde el ámbito de los estudios literarios, como uno más de los hechos relacionados a la producción literaria de un escritor o país.

\section{Problema}

Con esas ideas expuestas procuro una suerte de contextualización muy sucinta sobre el tema de los estudios en traducción literaria dentro del área centroamericana. Tal situación sugiere ya un problema inicial que atañe directamente al quehacer traductológico en nuestros países: la existencia de vacíos gráficos y materiales en cuanto al mismo objeto de estudio, producto de la falta de sistematicidad al documentar la actividad en cuestión (esto en las escasas situaciones en que se ha documentado). Lo cierto es que de común no se cuenta con fondos físicos o virtuales que contengan las traducciones realizadas, ni tampoco con inventarios bibliográficos que proporcionen al menos información básica acerca de tales obras (quién publicó, dónde, cuándo; quién fue el traductor, quién el editor; cuántos ejemplares se imprimieron, dónde se distribuyeron, etc.). Tampoco existen recuentos ni repositorios destinados a describir y alojar las obras derivadas de las traducciones: notas críticas, estudios, comentarios, notas introductorias o entrevistas, entre otras. 
Por otro lado, hay que reconocer que el abordaje del asunto de la traducción deliteraturacentroamericanadesde la perspectivatraductológica no es un desierto total. Desde hace algún tiempo se han realizado esfuerzos pioneros y serios dedicados al estudiodeltemaen cuestión, que sehan traducidoeninvestigacionesmuy valiosas. Demomentobastecon mencionar los trabajos de muy diversa índole realizados dentro del Plan deMaestríaen Traducciónde esta Universidad, las investigaciones sobre la traduccióndelasletrascentroamericanas realizadas porunconjuntode investigadores de la Universidad de Alicante en España, las recopilaciones y listados bibliográficos recolectados por diferentesestudiosos, y por supuestolos aportes en el campo que se han logradomediante iniciativas comolaque ahora nos acoge y otras similares, comoporejemploloscongresos organizados por la agit, de Guatemala.

Aun así, la labor por hacer todavía se encuentra en fases preliminares, tanto en términos cuantitativos como cualitativos. Así, de momento y en conjunto contamos con muy poca investigación de base. Por otra parte, hay que recalcar la falta de comunicación y coordinación en el tema entre los diferentes espacios que conformamos el área centroamericana. Bajo tales circunstancias, no es difícil vislumbrar que también haya vacíos de naturaleza fáctica — dada la escasez de datos fiables-y teórica, a raíz de la falta de teorización sobre el fenómeno en cuestión.

\section{Pregunta y objetivo}

A partir del panorama recién descrito surgen los cuestionamientos básicos que debemos hacernos en cuanto al futuro de los estudios de traducción literaria en el área; o, lo que es lo mismo, debemos preguntarnos hacia dónde debe proyectarse la actividad traductológica sobre las letras de la región. Pues bien, antes de delimitar posibles rumbos para nuestro propio quehacer, conviene mirar hacia afuera, y sondear las tendencias que se siguen en espacios con mayor tradición traductológica que los nuestros, no para seguirlas ciegamente, sino como punto de partida necesario. 


\section{Estado de los conocimientos en traductología sobre traducción literaria: temáticas y enfoques}

Lejos del panorama que ofrecía el clásico estudio crítico-comparativo entre "original" y traducción, en la actualidad los estudios en traducción literaria han diversificado su rango de intereses. Esto ha ocurrido a medida que, por una parte, se reconocía la multidimensionalidad de su objeto de estudio - en tanto traducción y a la vez texto literario- $-y$, por otra parte, se enfocaba dicho objeto desde diferentes ópticas al tiempo que se le ubicaba como parte de diversos fenómenos —el de la globalización, por ejemplo-. Paso ahora a nombrar algunos de los focos de interés en que se han estado concentrando los estudios en traducción literaria; para esto no he seguido ningún orden específico.

1. La historia de la traducción literaria. Esta rama de los estudios en traducción literaria tiene como sus objetos de estudio el desarrollo interno y externo de las literaturas nacionales a partir de la traducción, los traductores literarios, los autores y sus obras, los traductores/autores, el desarrollo teórico de base literaria, la traducción literaria en diferentes espacios y momentos históricos, la traducción literaria y su relación con distintos movimientos literarios, y la traducción de obras literarias trascendentales en el desarrollo de las sociedades, entre otros.

2. Traducción, poscolonialismo y literatura. La atención en esta rama recae principalmente sobre los colectivos minoritarios poscoloniales y su producción literaria, la traducción de esa producción literaria, el uso que en la actualidad le dan a la traducción literaria dichos colectivos, la recepción de sus literaturas en espacios hegemónicos, la manipulación del texto literario poscolonial, de la imagen de los colectivos poscoloniales a partir de la traducción y la retraducción de sus literaturas, y la visibilidad de los traductores y de la culturas minoritarias, entre otros también. 
3. Traducción, globalización y literatura. Muy en boga, quienes realizan estudios sobre estos temas se interesan en asuntos como la traducción y el traductor vistos como puentes culturales, la inserción de literaturas al ámbito internacional globalizado, la traducción literaria y la cuestión de la identidad, la industria editorial literaria globalizada, la traducción literaria como producto cultural de exportación e importación, las interacciones entre comunidades lingüísticas en el entorno internacional, el inglés como lingua franca en el ámbito literario, entre otros.

4. La traducción literaria y la teoría literaria. Dentro de esta rama se consideran asuntos relacionados a la evolución, complementariedad y aplicación de la teoría literaria dentro del campo de la traducción y su desarrollo.

5. Traducción, rasgos formales y políticas de traducción. Los estudios en esta temática se concentran en el análisis de la traducción de rasgos literarios específicos, los actores encargados y los entornos en que se realizan, la conformación de cánones literarios por medio de la traducción y el establecimiento de políticas, convenciones y normas que regulan la configuración y función de las traducciones producidas en determinados contextos sociohistóricos.

6. La traducción y el discurso literario. En este caso el análisis se concentra en los mecanismos de articulación del discurso literario en las traducciones, la adaptación de tales mecanismos según el propósito de las traducciones, la búsqueda de soluciones a problemas específicos, y los entornos culturales en que se realizan.

Cabe aclarar que este listado no es exhaustivo; muestra una idea general de las temáticas y objetos de estudio abordados por la disciplina sobre la cual discutimos en este momento.

Por otro lado, los estudios en todas las temáticas anteriormente citadas se abordan básicamente desde tres ópticas teórico-metodológicas bien delimitadas. Tales enfoques $-\mathrm{y}$ al citarlos me he servido de la clasificación que a propósito ha delineado Javier Franco, de la Universidad de Alicante - son los siguientes: el prescriptivista, el 
posestructuralista y el descriptivista. De tendencias prescriptivistas, según Franco, las tendencias más «intuitivistas», lingüísticas, pragmáticas y funcionales se centran en la búsqueda de soluciones que puedan aplicarse de manera sistemática, y por medio de las cuales se pueda producir - en términos relativos - la traducción óptima. Quienes acojan estas líneas de trabajo suelen centrarse en el método denominado «análisis de errores» o «crítica» de traducción. Según Franco, los estudios inscritos dentro de las corrientes posestructuralistas tienden a centrarse en el factor ideológico de la traducción (práctica y producto), en su impacto sobre el entorno productor y el receptor, y en la in-visibilidad del traductor, de la traducción y de los espacios de partida en el resultado final. Buscan evidenciar la función que tiene la traducción como medio de manipulación ideológica. Las temáticas relacionadas al poder, género, visibilidad y espacios marginales, entre otras, se analizan desde perspectivas feministas, deconstructivistas y poscoloniales.

Finalmente, los estudios que se realizan bajo la óptica descriptivista tienen como principal objetivo la producción de conocimiento nuevo, a partir de la aplicación de metodologías de base más científica, que permitan llegar a una mejor comprensión del fenómeno de la traducción, literaria en este caso. Las corrientes denominadas culturales, polisistémicas, historiográficas y sociológicas son las que mejor representan esta tendencia, siendo las dos últimas las de más reciente desarrollo. En última instancia, lo que buscan es dotar a la disciplina de una base teórico-metodológica de carácter científico y sistemático, que facilite la formulación de principios generales por medio de los cuales explicar el fenómeno de la traducción literaria.

\section{Propuesta}

Con un panorama más amplio, ¿qué dirección nos conviene tomar en cuanto a la actividad traductológica dedicada a nuestras letras? Dado el estado del conocimiento en cuanto a la traducción de nuestras 
literaturas —con sus vacíos materiales, fácticos y teóricos- ¿qué conviene más: delimitar una serie de directrices sobre la forma en que deberíamos traducir nuestras literaturas, analizar las influencias que las ideológicas dominantes de los polos de recepción han tenido sobre su traducción, o intentar conocer y comprender el fenómeno en todas sus dimensiones: contextuales, situacionales y textuales?

Por el momento, pienso que la primera opción no es la más adecuada en nuestro caso. En principio porque usualmente no hemos sido ni somos nosotros los que traducimos nuestra propia literatura. Tampoco me parece conveniente una orientación posestructuralista, ya que en última instancia tales enfoques también acaban por concluir que el traductor o las culturas de partida deben adoptar determinadas posiciones o estrategias a la hora de traducir sus literaturas, sin que todavía seamos nosotros los encargados de realizar tales traducciones. Así pues, en mi opinión debemos adoptar un enfoque descriptivista, y dentro de tal enfoque convendría de sobremanera favorecer las posiciones historiográfica y sociológica.

Presumo que esta combinación de descriptivismo, historiografía y sociología en traducción nos va a permitir llenar los vacíos de los que he venido hablando; desde luego, si seguimos un itinerario metodológico con fases claramente demarcadas, que implique la recolección de datos de naturaleza tanto cualitativa como cuantitativa, que conduzca a pasar del estudio de casos al de corpus, y que se centre, no en textos ni contextos de manera exclusiva, sino en los factores humanos que protagonizan la producción de dichos textos mientras interactúan con los contextos.

En un primer momento debemos dedicarnos a ubicar y recopilar las traducciones literarias que conformarán los corpus físicos de trabajo correspondientes a nuestras respectivas literaturas. La conformación de estos repositorios o fondos bibliográficos especializados, esta suerte de «arqueología» tal y como la definiera Anthony Pym, es pues un paso fundamental, como también lo es procurar 
su actualización constante y sistemática a medida que se producen nuevas traducciones.

Esta tarea nos dará una buena idea del itinerario histórico y lingüístico que ha seguido la literatura centroamericana. Pero, tan importante como lo que acabo de señalar, es que a partir de los corpus estaremos en posición de delimitar momentos y espacios de recepción específicos, editoriales y editores, autores y traductores, patrocinadores, agentes literarios, agentes editoriales, consultores, lectores meta y cualquier otro actor social involucrado con la producción de las traducciones recopiladas. También podremos darnos cuenta del tipo de literatura y autores centroamericanos que se ha estado traduciendo, sus estilos, tendencias y capitales simbólicos dentro de la palestra literaria local e internacional.

En una segunda fase nos corresponderá extraer y procesar datos específicos. Mediante estos procesos de sistematización de la información podremos identificar actores, mecanismos y factores protagónicos en la producción de las traducciones de literatura centroamericana, así también como intereses dominantes, propósitos, funciones específicas, tendencias de selección de autores y literaturas, tendencias traductoras, tendencias paratextuales, tendencias formales específicas, e imágenes proyectadas a través de las traducciones, entre otros.

En una tercera etapa y a partir de las dos anteriores estaremos en capacidad de empezar la correlación de perfiles contextuales de orden poético-literario, político, económico y académico- con comportamientos situacionales y textuales. Todo con el objetivo de inducir las políticas que han regido las migraciones de nuestras literaturas en el tiempo, el espacio y las lenguas.

Por supuesto, un cuarto paso consistiría en la suma de experiencias. La comparación y correlación de los estudios que realicemos de manera local pero bajo una óptica común nos permitirían pasar de los meros resultados a la formulación de una serie de máximas que podríamos extrapolar, si no al fenómeno de la traducción 
literaria como un todo, al menos sí al de la traducción de literaturas minoritarias. La teorización sería pues el resultado final y más deseable del proceso hasta ese punto.

La puesta en marcha de tal esfuerzo conjunto implica la previa apertura de espacios de discusión y cooperación. Se requiere entonces y desde ya la instauración de vínculos interuniversitarios o interinstitucionales, la integración y coordinación de grupos de investigación, el intercambio de datos y resultados, y la creación de programas de investigación, todo en el ámbito regional.

Una vez que se ha pasado por todos los anteriores procesos, se podría pensar en retroalimentar la rama pedagógica a partir de la experiencia investigativa. Así, una última etapa consistiría en la integración de hallazgos y conclusiones a los planes de estudio y programas de formación, ahora sí en la forma de propuestas de carácter prescriptivo, que al fin de cuentas nos podrían permitir ofrecer nuestras propias traducciones de la producción literaria de nuestros países.

Es este pues, en pocas palabras, el camino que debería tomar la actividad traductológica regional al abordar el tema de la traducción de la literatura centroamericana. Es una labor arqueológica, descriptiva y explicativa que, desde la historiografía y sociología de la traducción, nos puede conducir a apropiarnos de una práctica traductora - como ha ocurrido en otros espacios-, incluso a posicionarnos como región en el campo de la traductología, desde el ámbito de la traducción literaria. 